\title{
Design of a Force Measurement System Implemented on a Computer: Computerized Dynamometer
}

\author{
Camilo Chamorro Rivera \\ Research Group on Instrumentation, Automatic Control and \\ Robotics (ICARO), Research Seedbed on Automation \\ Faculty of Engineering \\ Politécnico Colombiano Jaime Isaza Cadavid, \\ El Poblado - Medellín, Colombia
}

Icchamorro@elpoli.edu.co

\begin{abstract}
This paper presents the design of a force measurement system implemented on a computer, also known as computerized dynamometer. The specific objectives are: measurement force of up to 8 sensors at the same time, determine the maximum force during a test, implement alarms from overload, and design a unique graphic registration system in the time. It shows the electronic design (Hardware) and the design of the computer program (Software). The designed system is implemented in an equipment of physical training with elastic bands, called MULTIBAND ${ }^{\circledR}$, improving the equipment in terms of the measurement of the physical variables developed during the training of up to 8 users. This work is considered as application in engineering.
\end{abstract}

Keywords: measurement of force, dynamometer, load cell, data acquisition, virtual instrument.

\section{Introduction}

The objective of this work is to design a computerized force measurement system that allows to measure in real time the forces of up to 8 sensors simultaneously. This system should also function like research platform for future works in the areas of instrumentation and metrology.

The origin of this project arises when there is the need to measure force of up to 8 users in physical training MULTIBAND ${ }^{\circledR}$ system. Initially contemplated taking a measurement with mechanical dynamometer, as shown in Figure 1, but was limited to only use the indication, also had to

have as many instruments as users,

Material published as part of this publication, either on-line or in print, is copyrighted by the Informing Science Institute. Permission to make digital or paper copy of part or all of these works for personal or classroom use is granted without fee provided that the copies are not made or distributed for profit or commercial advantage AND that copies 1) bear this notice in full and 2) give the full citation on the first page. It is permissible to abstract these works so long as credit is given. To copy in all other cases or to republish or to post on a server or to redistribute to lists requires specific permission and payment of a fee. Contact Publisher@InformingScience.org to request redistribution permission.

which complicated the solution.

The possibility of implementing digital dynamometers was analyzed. Those of internal sensor resembled the mechanics. Those of external sensor allowed more chances, but were still limited in that only sense force of a sensor at the same time. Referring to the State of the art, found that there were different solutions to this problem, using a computer. 
For example, were found designs of dynamometers for the evaluation of muscle function in rehabilitation medicine (Harlaar, Roebroeck, \& Lankhorst, 1996), or the design of a system of registration and display of the force applied to a biological tissue (Farinas, Maltos ,\& Astudillo, 2001).

In terms of applications of computerized dynamometers multiple cases are found in all areas of engineering, for example, in the automotive area (Leonard \& LaVerghetta, 1986), biomedical, construction, etc.

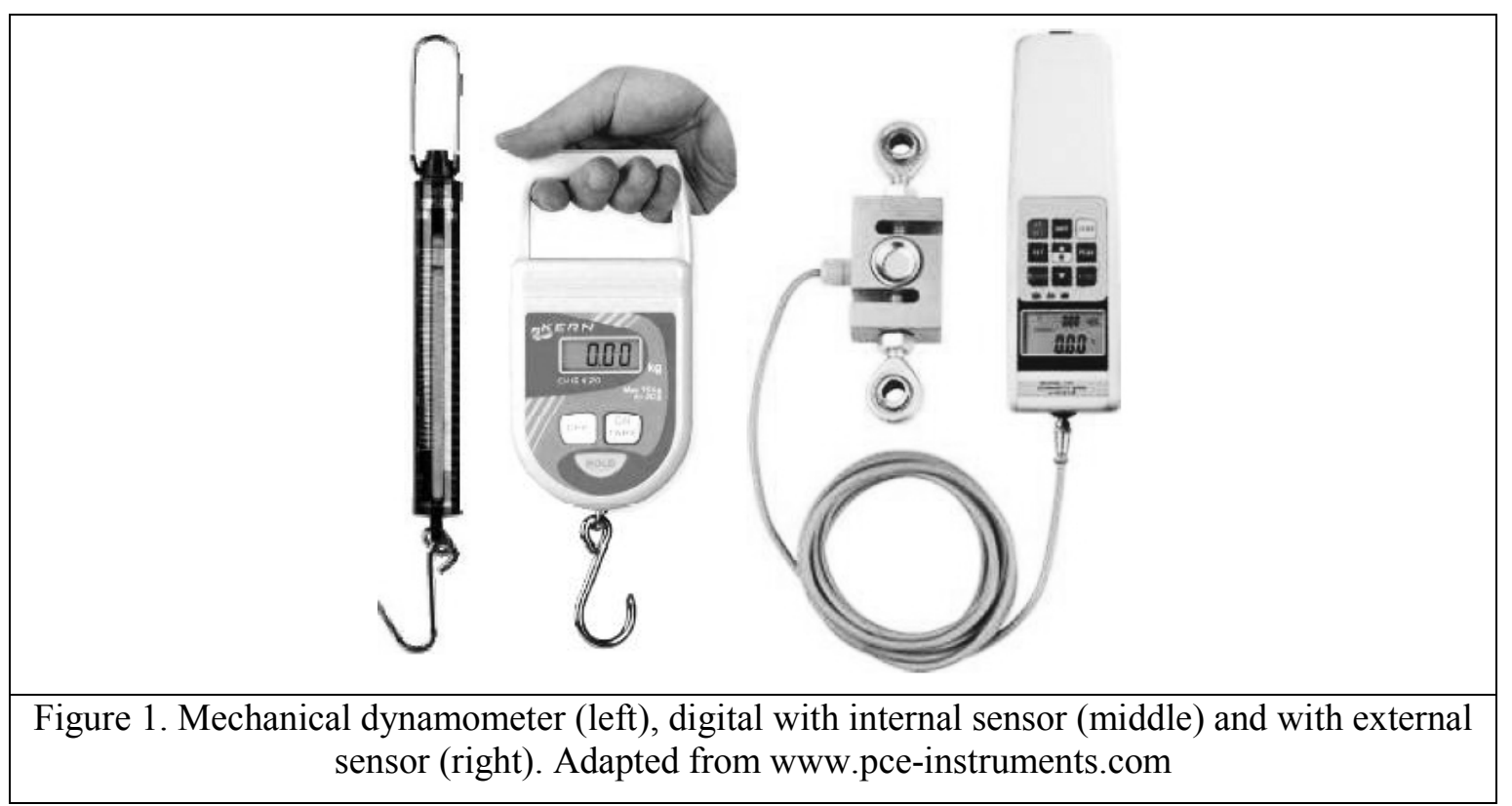

But all the examples seen not found a design measurement multiple force sensors at the same time. That's why it was determined to implement this system of measurements on a computer, in addition to the advantages of a modern computer system: communications, peripherals, operating system multitasking, etc.

The work was divided into three stages:

- Electronic design of the system (Hardware).

- The computer program design (Software) for force measurement.

- Implementation in physical training equipment.

\section{Electronic System Design}

\section{Sensor of the Force Measurement System}

Within commercial sensors for the measurement of force, it was decided to modern sensors based on load cells, which have a wide application in various processes. Figure 2 shows a force sensor type load cell.

Applications are for example found in research on the measurement of Young's modulus in rubber (Rayas, Rodriguez-Vera, \& Martínez, 2003), in the field of materials for civil works (Martel, Cordero, Benito, \& Danesi, 1999), measurement and control force in robots, in Biomechanics applied to yew as discipline Sports and in countless industrial processes, as for the determination of the weight of tanks, hoppers, silos, and scales, among others. 
Based on this background and due to the good characteristics of instrumentation: accuracy, precision, sensitivity, linearity and mechanical resistance, proven in these applications and by the same manufacturer, it was decided to select load cells, as the best sensors used in this work for the measurement of force.

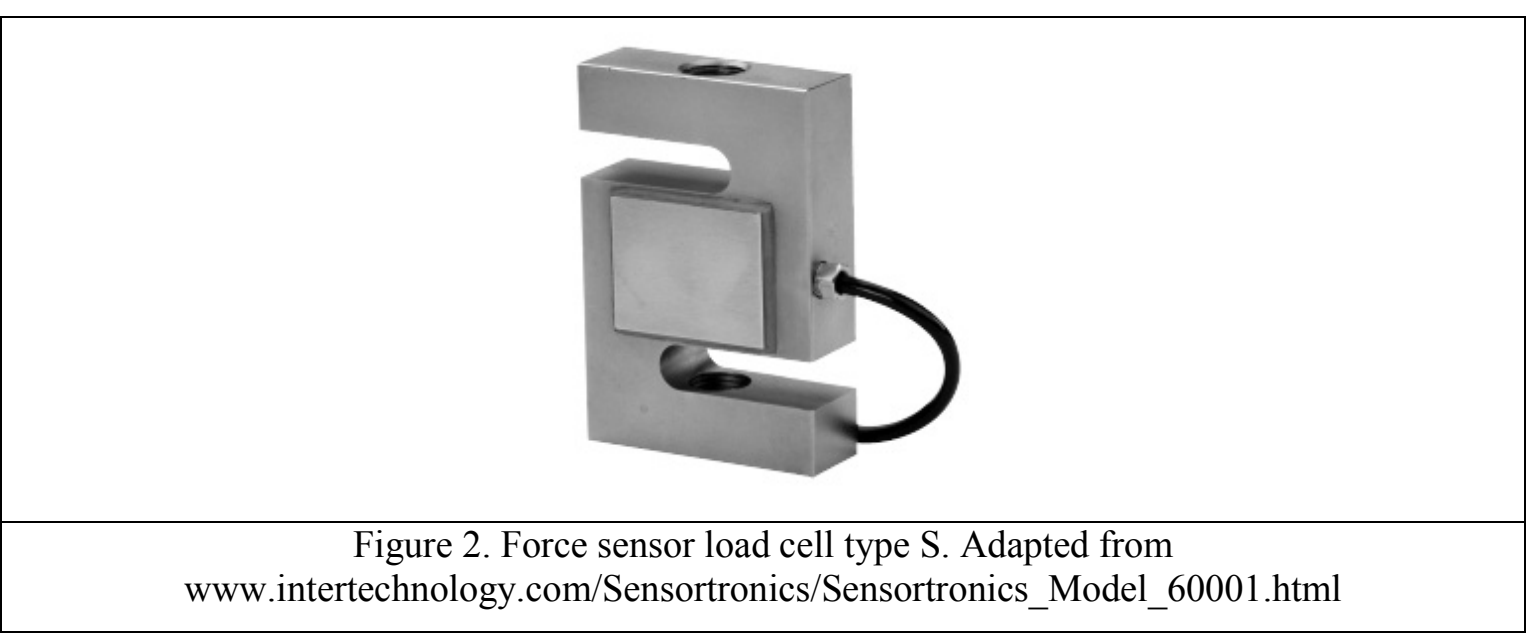

A load cell is composed of a metallic elastic element within which various gauges connected in the form of (Special circuit of electric resistances) Wheatstone Bridge are inserted. When applying an external force distorts the element, producing a variation in the resistance of the electrical circuit formed by gauges, generating an electrical signal proportional to the deformation produced.

Load cells commercially come in a variety of presentations ("Wim Load Cells", 2012). For the project a presentation type $\mathrm{S}$ is used in the implemented application is measured tensile force, and in addition this type has a low-cost commercial, but for other applications load cells can be used for example for torque, compression, and other types.

Some features of the load cells used are:

- Span: 200 Lb-f (pounds-force) F.S: Full Scale

- Accuracy: 0.02\% (F.S)

- Accuracy: $0.02 \%$ (F.S)

- Linearity: $0.02 \%$ (F.S)

- Sensitivity: $0.2 \%$ (F.S)

- Mechanical Overload: 150\% (F.S)

\section{Component Parts of Dynamometry System}

The elements that compose the measurement system are:

- Eight force sensors, to measure more than one force at the same time. Measurement principle: load cell with strain gauge, type: $\mathrm{S}$, analog signal of 0 to 2 millivolts per volt, 5 volt power.

- An electronic board (Figure 3) that contains:

$\circ$ A conditioning circuit of voltage signals sent by the sensors. It contains source, filters and instrumentation amplifiers, since signals are low voltage and very immune to electrical noise.

- A data acquisition system based on microcontroller, built by one of the researchers of the ICARO research group (Gomez, 2011), P-TAS S01 reference, with its cable and 
connector: eight 10-bit analog inputs, up to 2 analog outputs, 25kS/s, 15 lines digital TTL ( 8 inputs, outputs 7), USB 2.0 communication port.

- A built-in computer of good operating characteristics (RAM memory, hard drive, processor, etc.), with integrated touch screen. Due to the touchscreen peripherals such as keyboard and mouse is not required.

An electronic board with the amount of necessary inputs is used for the data acquisition system and that meets the minimum requirements of acquisition speed for processing, in real time, force measurement program.
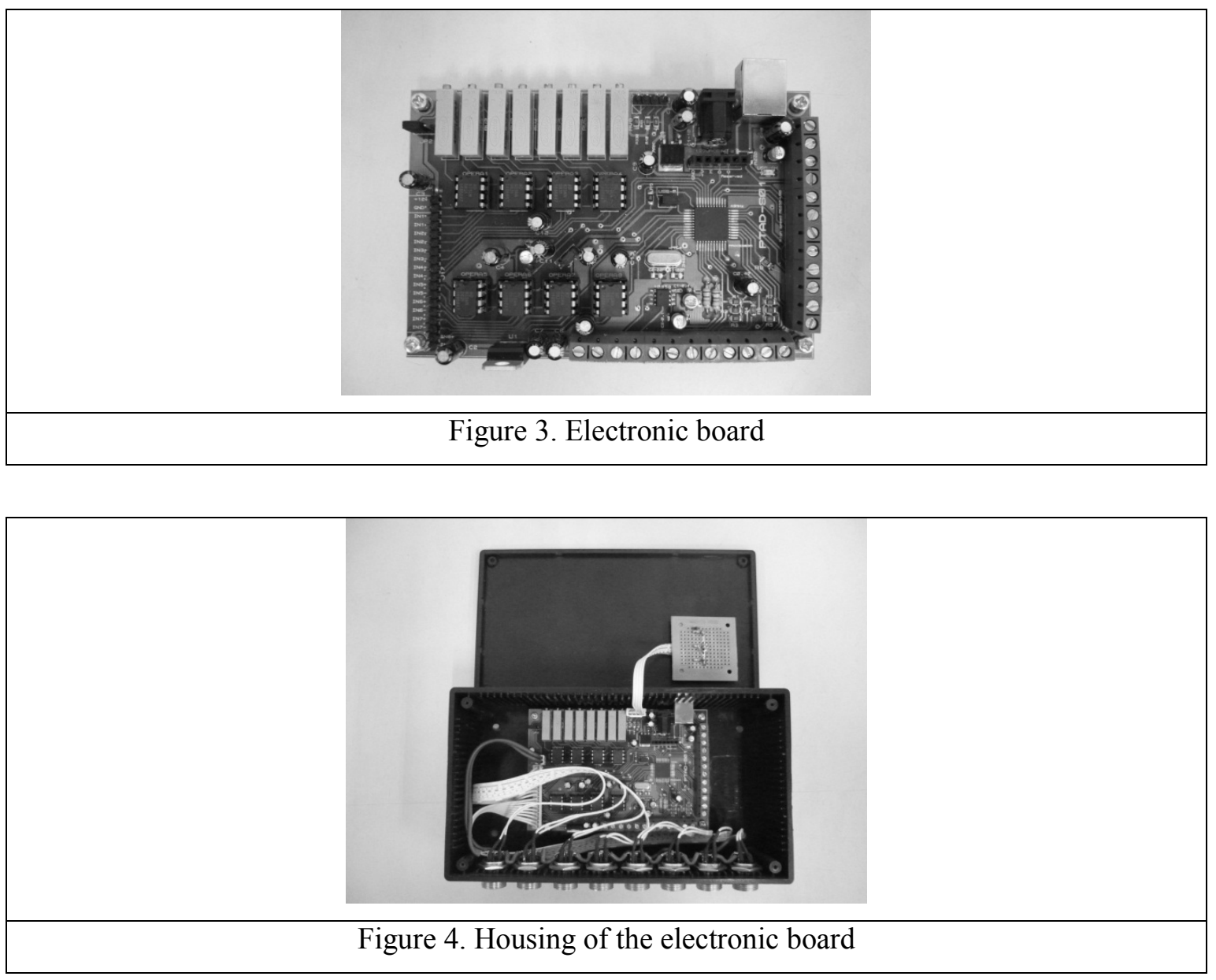

Figure 5 shows a block diagram of the different stages of the electronic board, which shows the interconnection between the various circuits. 


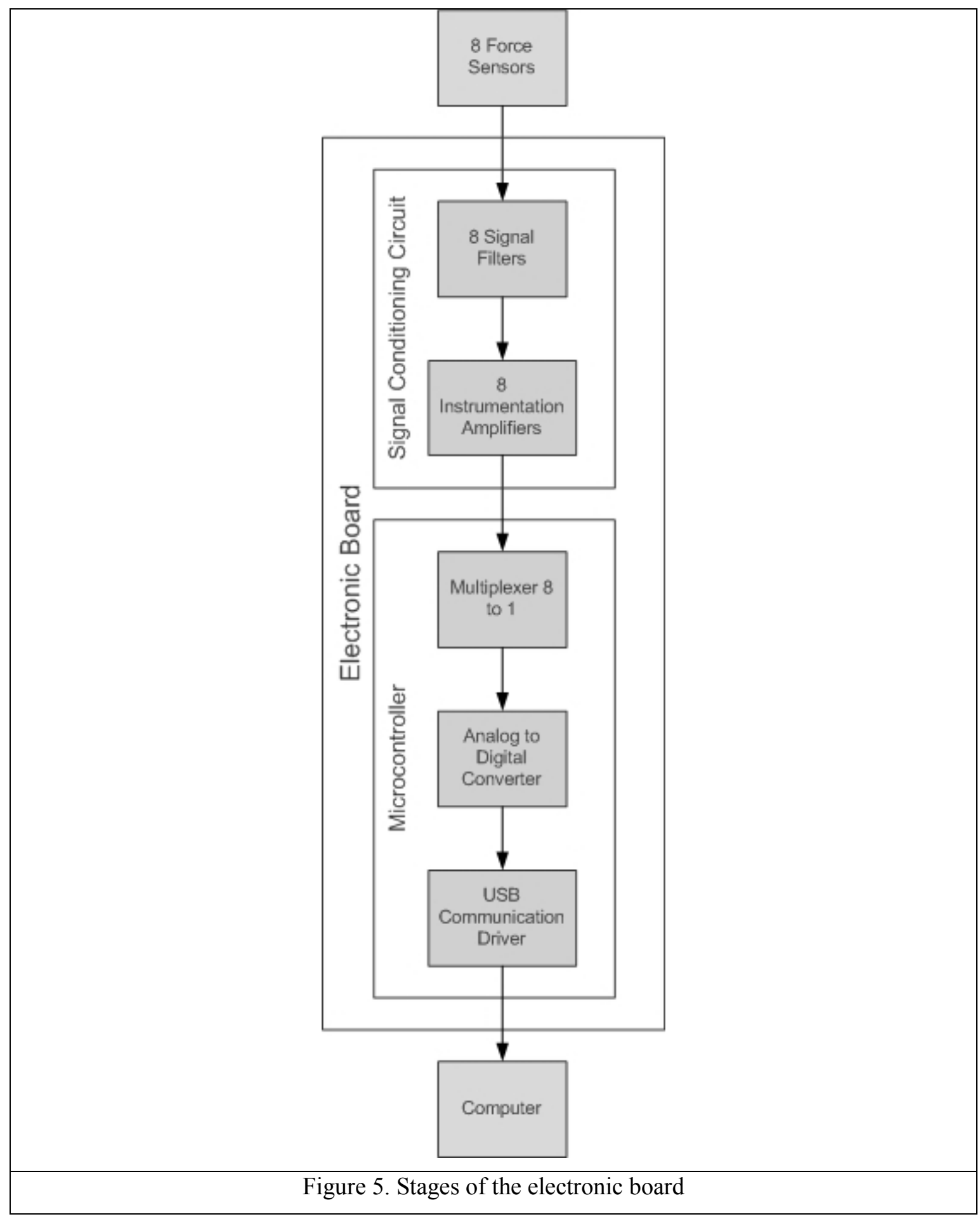

The final idea is that the project is commercial, so it was designed a housing with an aesthetically pleasing presentation to the end user. Indicators of state they were at the front of the instrument, and laterally were, in the upper part the USB communication port, and at the bottom, ports in connection with the 8 sensors of force. This design can be seen in figures 6 and 7 . 

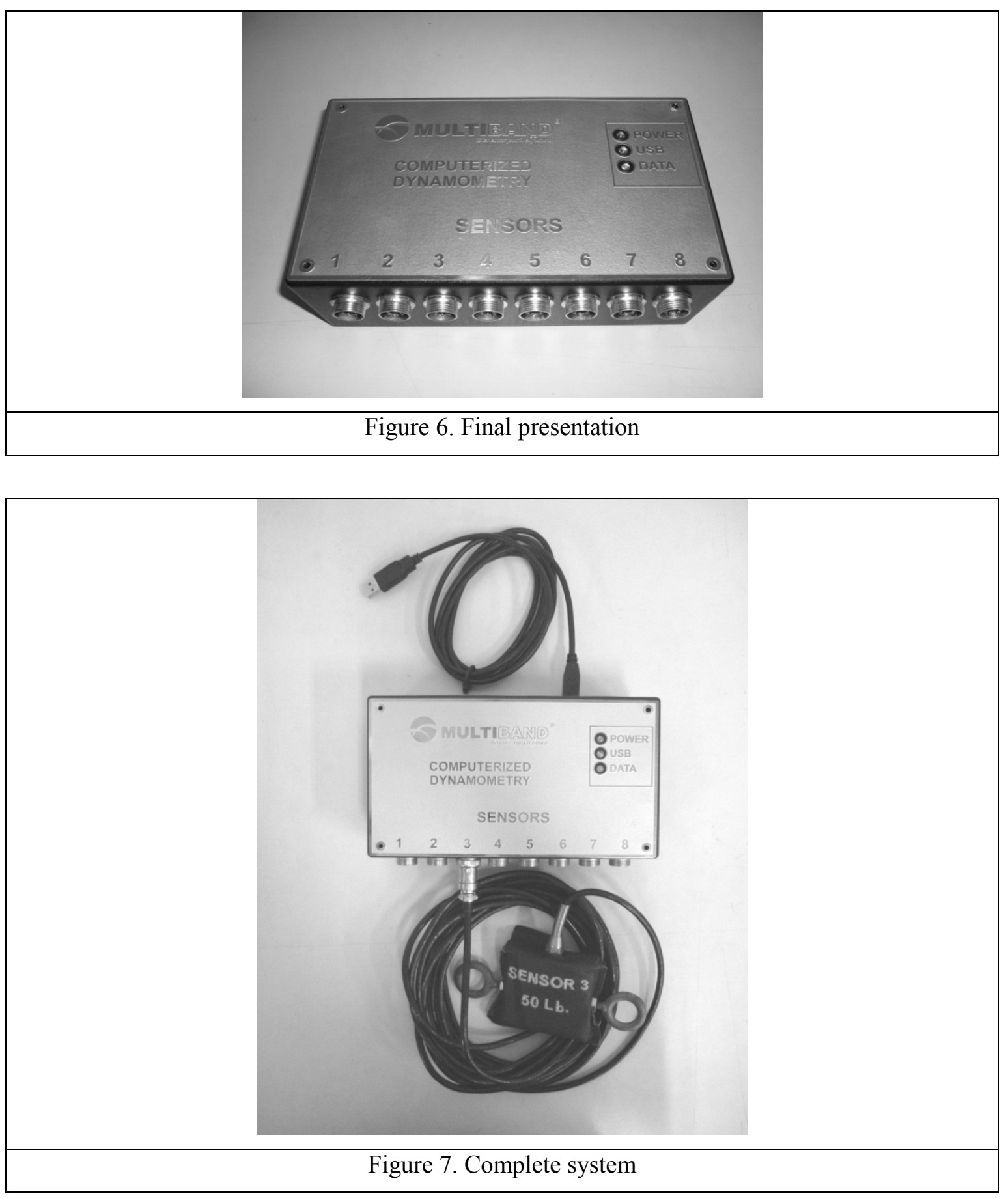

Requirements for the computer are mainly the speed of processing and communication with the data acquisition system, so a modern computer is sufficient.

A type of integrated computer known as "All in one" was chosen. This type of computer that integrates in one box all components of hardware, i.e. CPU, screen, keyboard, and does not need mouse since it is touchscreen. 


\section{Design of Computer Program}

The computer program is designed in a graphical programming language that allows the indication and registration in real time of the force exerted by the users. It also has programmable overload sensors that warn visually and with sound when it has reached these thresholds, in order to protect the sensors and alarms to the source generating the force (Figure 8).

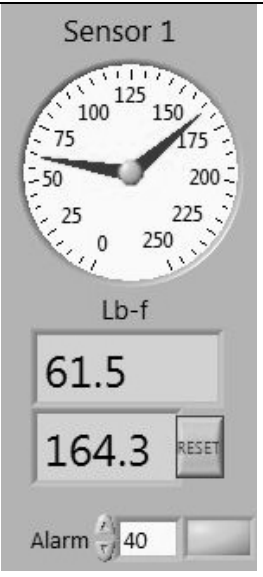

Figure 8. Indicator of current force and maximum force, with visual and audible alarm

Graphic recorder shows the behavior of each force sensor in the time (Figure 9). The lines on the graph of each sensor are differing with colors.

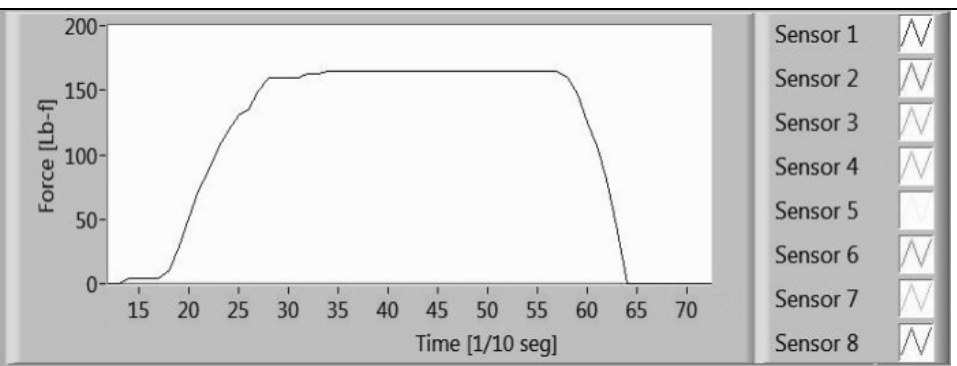

Figure 9. Force graphic register for each sensor 
The presentation of the program has a user friendly interface, as shown in Figure 10.

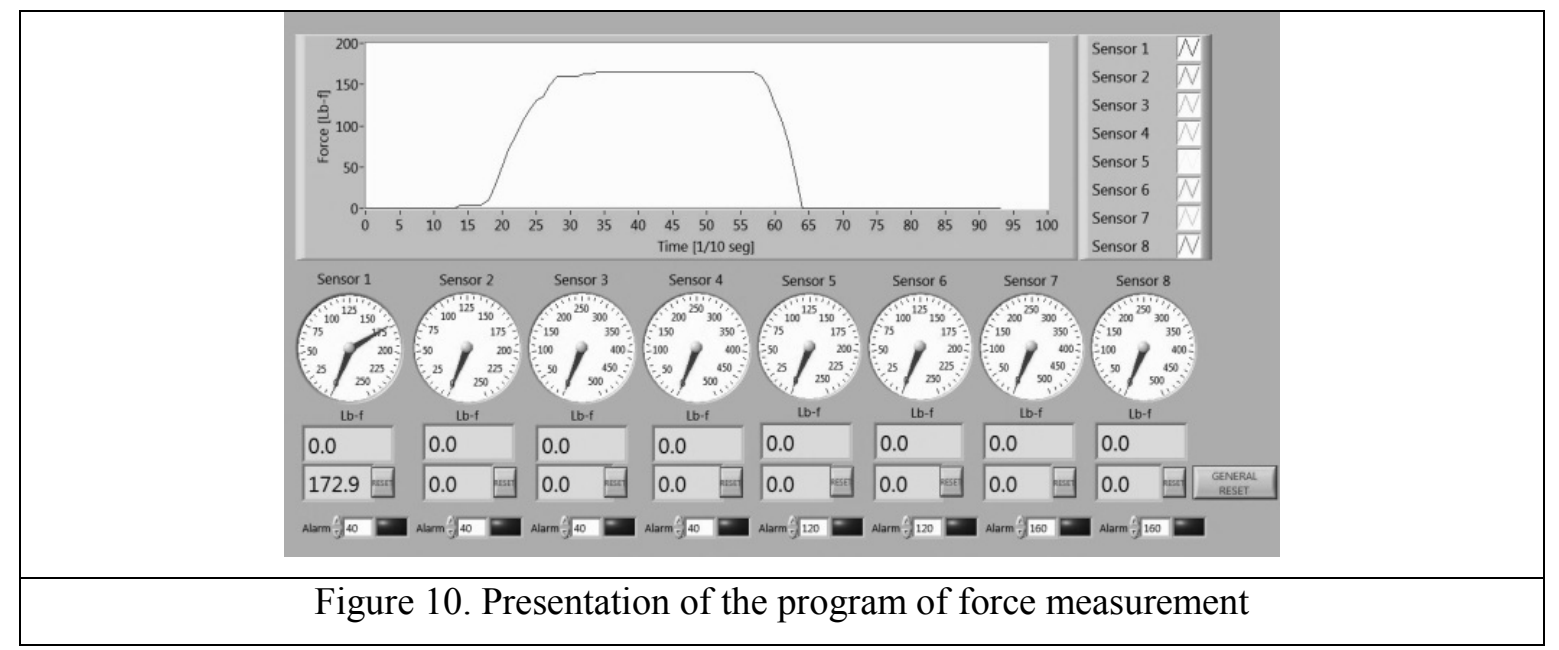

\section{Application in Multiband $囚$ Fitness Equipment}

An application of computerized dynamometer was implemented in MULTIBAND ${ }^{\circledR}$ fitness equipment (Ortega, 2011). This equipment has a design that uses bands and elastic tubes as resistance generating elements, instead conventional elements such as weights.

Commercially the elastics are differentiated by resistance grades according to a color code, allowing changing color when required, without having to add more bands to increase resistance. For example, in the table 1 shows the relationship between stretching and resistance generated for some elastic bands ("Resistance Band", 2012).

\begin{tabular}{|c|c|c|c|c|}
\hline Stretch & Yellow & Green & Black & Golden \\
\hline $50 \%$ & 0.8 & 1.5 & 2.9 & 6.3 \\
\hline $100 \%$ & 1.3 & 2.3 & 4.4 & 9.8 \\
\hline $150 \%$ & 1.8 & 3.0 & 5.6 & 12.5 \\
\hline $200 \%$ & 2.2 & 3.6 & 6.7 & 15.2 \\
\hline $250 \%$ & 2.6 & 4.4 & 8.0 & 18.2 \\
\hline
\end{tabular}

Design of the MULTIBAND® equipment consists of an iron frame which is fixed to a wall, with 16 pins giving a resistance of 100 kilograms-force traction. In the figure 11 this design can be seen. 


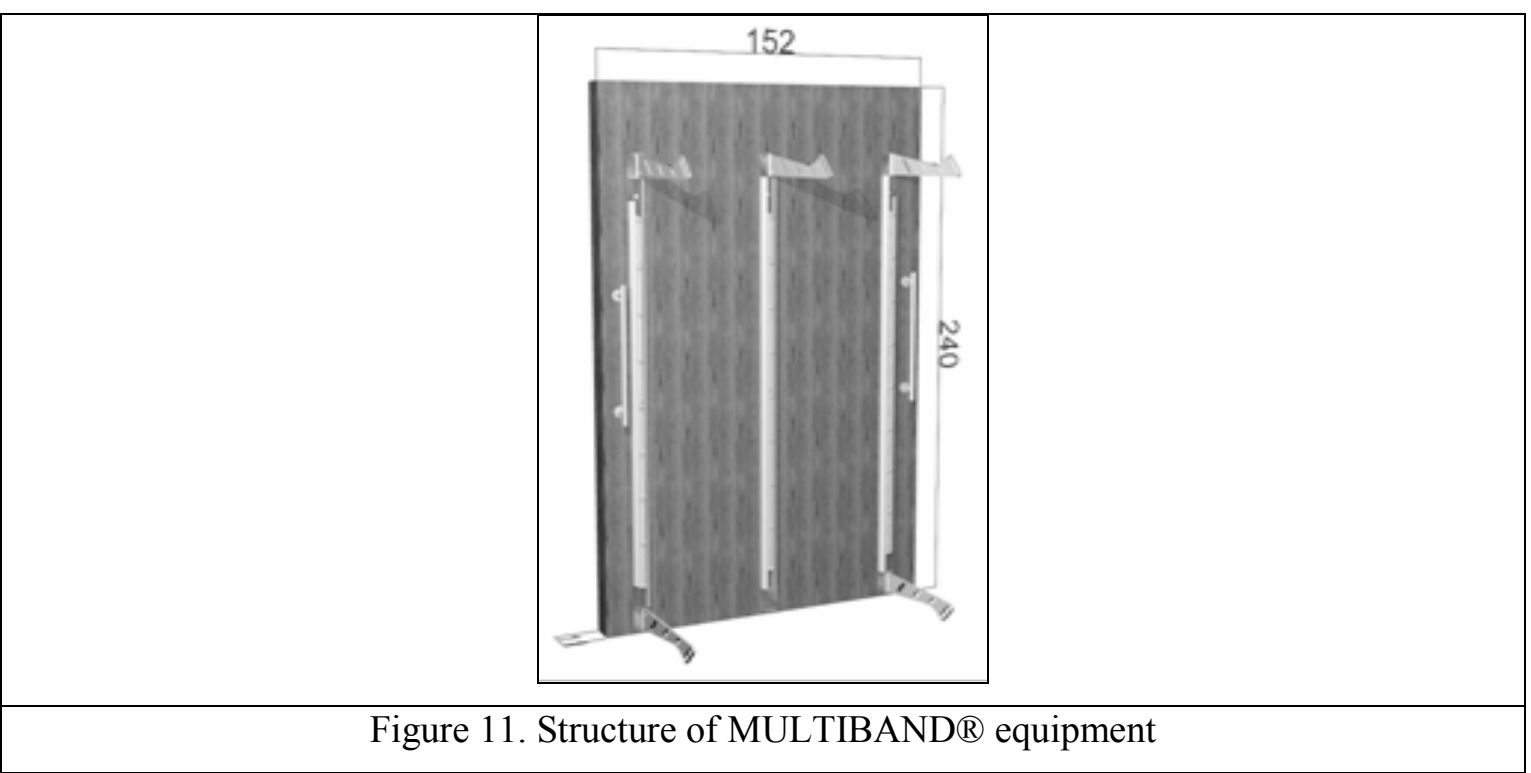

This structure is designed to adhere to her five arms in stainless steel, each of them with five perforations. Three of the five arms are located in the upper part, and allow classic exercises like: triceps, back, shoulder, side oblique, replacing high pulleys. The other two arms are located in the lower part, and allow basic exercises of: biceps, butt, back, shoulder, trapeze, squat, quadriceps, adductor, abductor, hamstrings calf. This system is complemented with a chair with 2 arms that allows exercises in sitting position (Figure 12).

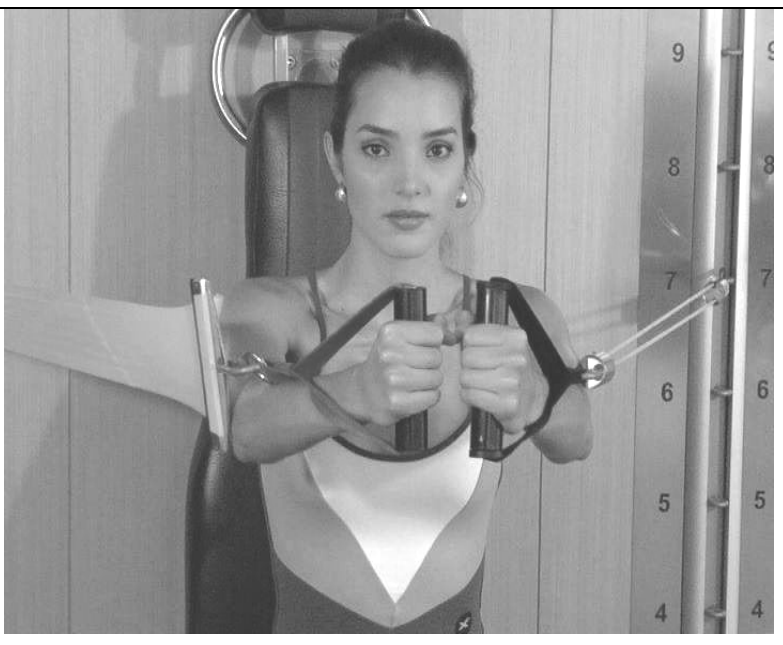

Figure 12. Rubber band (left) and tube (right) with MULTIBAND® equipment attachments

Covering the metal structure, it carries a wooden panel mesh natural oak attached to the structure, and eight terminals in stainless steel with marks in numbers, allowing identifying points of attachment for the development of the exercise. In the upper part of the chair joined the computer that runs the force measurement program, as shown in Figure 13. 

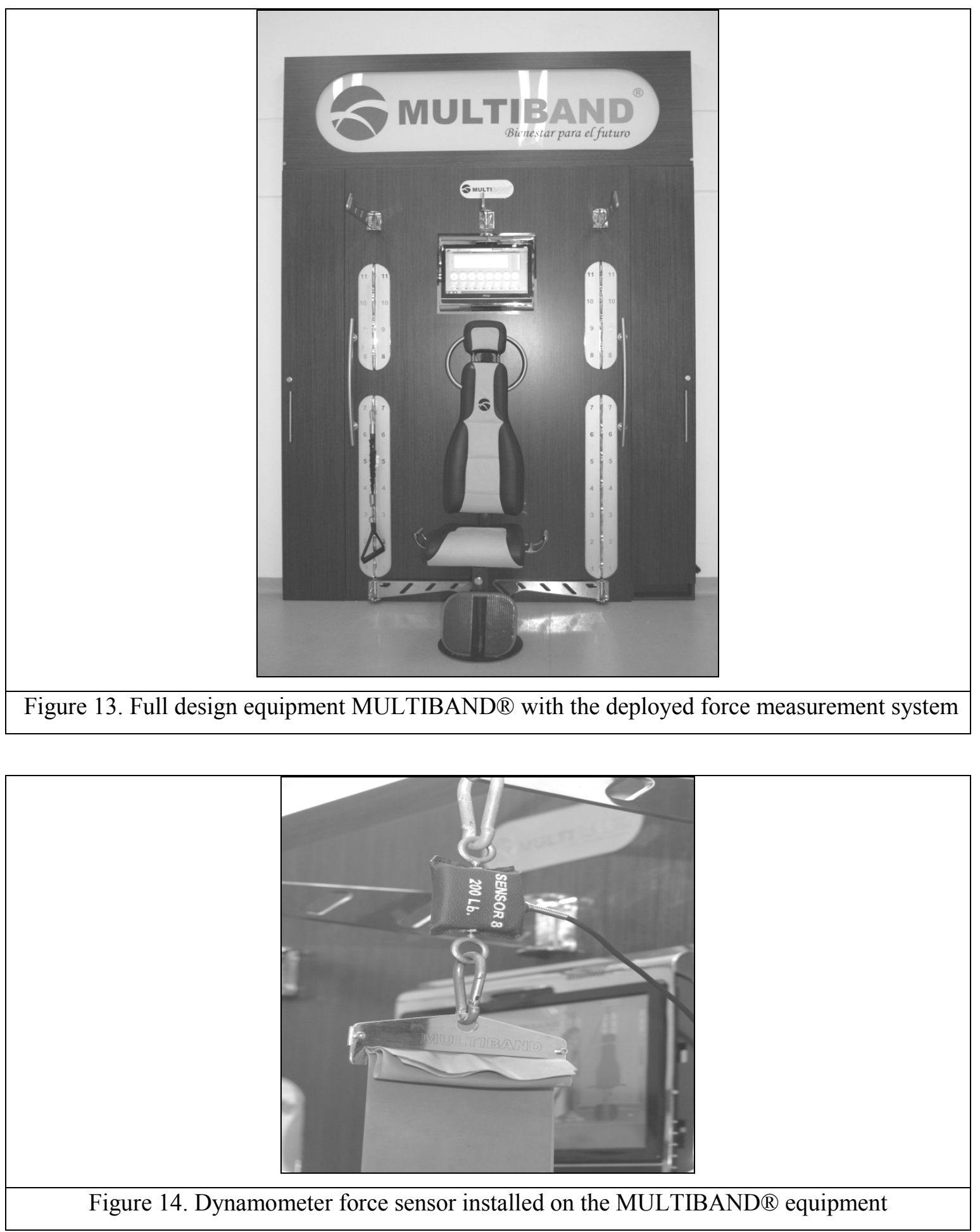

\section{Conclusions}

- $\quad$ The force measurement system meets the objectives of design, i.e., measures force of up to 8 sensors at the same time, determines the maximum force of each sensor during a test, implements overload alarms and records at the time in a unique graph the sensed forces. 
- Force measurement is done in real time since a very low, almost imperceptible sampling period is used for the user.

- The final sensitivity of measurement of force is determined by the sensitivity of the sensor, since other elements have a lower sensitivity. In this case, the sensitivity of the A/D converter is $0.01 \%$, but the sensitivity of the whole system is $0.4 \mathrm{Lb}-\mathrm{f}$ (Pound-force) for a range of 200 Lb-f, since the sensitivity of the sensor is $0.2 \%$.

- Computerized dynamometer requires less space than some traditional instruments, therefore less economic investment.

- The computer system becomes a platform to implement other future applications. It will allow for example:

- Designing a wireless system for force sensors.

- Having repetitions indication, monitoring the exercises with the webcam, and sound of increased force.

- Evaluate the power of each exercise and have historical values, for example for the selection of talented athletes.

- Schedule the performed exercise yields and maintain data accumulated for each user according to its process of training routines.

- Set up profiles and performance of users and present monitor of progress of the parameters of force and power.

- Prescribe training according to the needs of each user.

\section{References}

Farinas, W., Maltos, L., \& Astudillo, N. (2001). Registration system and visualization of the force applied to a biological tissue. Memories II Latin American Congress of biomedical engineering. Havana, Cuba. Retrieved February, 2013 from http://www.hab2001.sld.cu/arrepdf/00328.pdf

Gomez, J. (2011). Data acquisition system. Retrieved August, 2013 from: http://sites.google.com/site/controlpoli2/hardware

Harlaar, J., Roebroeck, M., \& Lankhorst, G. (1996). Computer assisted hand held dynamometer: Low cost instrument for muscle function assessment in rehabilitation medicine. Medical \& Biological Engineering \& Computing. 34(5), 329-335. Retrieved June, 2013 from: http://www.ncbi.nlm.nih.gov/pubmed/8945855

Leonard, L., \& LaVerghetta, F. (1986). Dynamometer testing under computer control. SAE Technical Paper 680131. Retrieved May, 2013 from: http://papers.sae.org/680131

Martel, J., Cordero, M., Benito, R., \& Danesi, R. (1999). Effects of corrosion in prestressed concrete elements. Article of the structures laboratory, Mendoza, Argentina: National University of Tucumán.

Ortega, A. (2011). System of physical training with elastic band MULTIBAND®. Retrieved August, 2013 from: http://multibandequipos.blogspot.com

Rayas, J., Rodriguez-Vera, R., \& Martínez, A. (2003). Measurement of Young's modulus in rubber latex using ESPI. Article: in Revista Mexicana de Física $\mathrm{N}^{\circ}$ 49. Mexico: Optics Research Center. pp. 555564.

Resistance Band \& Tubing Instruction Manual. (2012). Retrieved August, 2013 from: http://www.theraband.com/instructions.php

Wim Load Cells: Weigh Sensors. (2012). Retrieved July, 2013 from: http://www.wim-systems.com/loadcells.html 


\section{Biography}

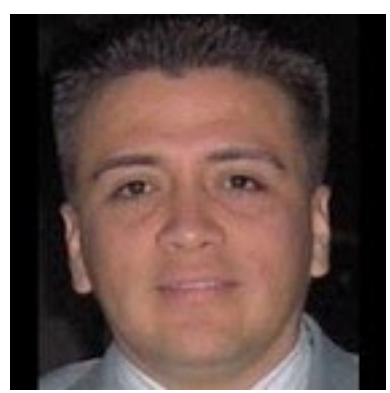

Camilo Chamorro Rivera is Associate Professor in the Politécnico Colombiano Jaime Isaza Cadavid in Medellin, Colombia. Also is Instrumentation and Control Engineer from the same institution.

He is Automation specialist and Master of Engineering from Universidad Pontificia Bolivariana. He has experience in industrial instrumentation, automatic control, electronic design and software development.

He has developed applications in the industrial field and in biomedicine. 